\title{
Association between TV viewing and heart disease mortality: Observational study using negative control outcome
}

Mark Hamer, ${ }^{1}$ Ding Ding ${ }^{2,3}$, Josephine Y. Chau ${ }^{2,3}$, Mitch J. Duncan ${ }^{4,5}$, Emmanuel Stamatakis ${ }^{2,3}$

${ }^{1}$ Institute Sport, Exercise \& Health, Division Surgery Interventional Sciences, Faculty Medical Sciences, University College London, London, United Kingdom.

${ }^{2}$ Charles Perkins Centre Epidemiology Unit, University of Sydney, Sydney, Australia.

${ }^{3}$ Prevention Research Collaboration, School of Public Health, University of Sydney, Sydney, Australia.

${ }^{4}$ Priority Research Centre for Physical Activity and Nutrition, The University of Newcastle, University Drive, Callaghan NSW, Australia.

${ }^{5}$ School of Medicine \& Public Health, Faculty of Health and Medicine, The University of Newcastle, University Drive, Callaghan NSW, Australia

${ }^{*}$ Correspondence: Prof Mark Hamer, 43-45 Foley street, Division Surgery Interventional Sciences, UCL Faculty Medical Sciences, University College London, London, UK. Email: m.hamer@ucl.ac.uk

Word count $=1,534$

Licence for Publication

The Corresponding Author has the right to grant on behalf of all authors and does grant on behalf of all authors, an exclusive licence (or non exclusive for government employees) on a worldwide basis to the BMJ Publishing Group Ltd to permit this article (if accepted) to be published in JECH and any other BMJPGL products and sublicences such use and exploit all subsidiary rights, as set out in our licence

Competing Interest: None declared. 


\section{Abstract}

Aims: Sedentary behaviour (particularly TV viewing) is thought to be a risk factor for cardiovascular disease. We employed a negative control outcome to explore if the association between TV viewing and heart disease mortality is explained by confounding.

Methods: The sample was drawn from the UK Biobank study and comprised 479,658 participants (aged $56.5 \pm 8.0 \mathrm{yrs} ; 45.7 \%$ male) followed up over a mean 10.4 years. TV viewing was measured from self-report.

Results: There were 1,437 ischemic heart disease (IHD) deaths, and 214 accidental deaths (employed as the negative control outcome). TV viewing was related to the following confounding variables: age, smoking, alcohol, diet, obesity, physical inactivity, cardiovascular disease and education. The confounding structures were similar for both outcomes. TV viewing (per $\mathrm{hr} / \mathrm{d})$ was associated with $\mathrm{IHD}(\mathrm{HR}=1.30,95 \% \mathrm{Cl}, 1.27,1.33)$ and accidental death ( $\mathrm{HR}=1.15 ; 1.07,1.24)$ in unadjusted models. Associations were attenuated for both outcomes and were considerably converged after adjustment for confounders; IHD $(1.09 ; 1.06,1.12)$ and accidental death $(1.06 ; 0.98,1.15)$.

Conclusion: The pattern of results for TV with an implausible outcome mirrored that of IHD, suggesting that observed associations between TV and heart disease are likely to be driven by confounding.

Key words: Sedentary; Negative control; Mortality; Heart disease; Population 


\section{What is already known}

- Observational data suggest an association between sedentary behaviour (particularly TV viewing) and health outcomes.

\section{What this study adds}

- We employed a negative control outcome to explore if the association between TV viewing and heart disease mortality is explained by confounding.

- The pattern of results for TV with an implausible outcome (accidental death) mirrored that of heart disease.

- $\quad$ Observed associations between TV and heart disease are likely to be driven by confounding. 


\section{Introduction}

Sedentary behaviour has been linked to detrimental health effects although the area has attracted debate due to inconsistencies in how the evidence base was developed and interpreted. ${ }^{1}$ Much of the early ${ }^{2,3}$ and ongoing ${ }^{4,5}$ work in this area used Television (TV) viewing as a marker of sedentary behaviour. Indeed, TV viewing has been consistently associated with risk of heart disease mortality in population cohort studies ${ }^{4,6-9}$ after adjustment for a range of confounding variables. These results, however, are difficult to interpret as residual confounding remains a major concern and biological plausibility has not been well established; that is, the mechanisms linking TV time and heart disease are largely unknown as recent work showed that adjustment for biomarkers including lipids, glucose control and inflammation did not substantially alter the associations. ${ }^{10}$

Statistical adjustment is a common technique to deal with confounding in observational epidemiology, although key covariates are often not measured or measured with inaccuracy (e.g., self-reported diet, underlying disease). Negative control comparisons are increasingly recognised as a means of strengthening causal inference in observational study settings. ${ }^{11} \mathrm{~A}$ negative control reproduces a condition that cannot involve the hypothesized causal mechanism but does involve the same sources of confounding that may bias the relevant association. If, for example, TV viewing was comparably associated with an appropriate negative control (implausible) outcome as with the primary (more plausible) outcome, this suggests that the association with the primary outcome is generated through pervasive confounding (e.g. is non-causal). We selected accidental death as a negative control outcome as we believed that accidents would be randomly distributed in relation to TV viewing habits yet display a similar confounding structure.

The aim was to explore if the association between TV viewing and ischemic heart disease (IHD) mortality is explained by confounding through employing a negative control outcome in a large population cohort. 


\section{Methods}

Participants

Participants aged 40-69 years were recruited in 2006-2010 as part of the UK Biobank study and attended one of 22 clinical assessment centers in England, Wales, and Scotland. ${ }^{12}$ Ethical approval was provided by the National Health Service, National Research Ethics Service (Ref 11/NW/0382).

TV viewing and covariates

TV viewing was included as a single item during the touch screen questionnaire "In a typical day, how many hours do you spend watching TV? If the time you spend watching TV varies a lot, give the average time for a 24-hour day in the last 4 weeks." Physical activity was assessed using the International Physical Activity Questionnaire (IPAQ) short form ${ }^{13}$ that measures duration and frequency of moderate-to-vigorous physical activity from all domains in the last week. Total Metabolic Equivalent (MET)-min per week was calculated from walking, moderate and vigorous physical activity. Other data collected via self-report included age, sex, smoking history (Never, ex-smoker, current), frequency of alcohol intake (daily or almost daily, 1-2 times a week or monthly, never or almost never), fruit and vegetable consumption (none, 1, 2, 3, $\geq 4$ portions a day), educational attainment (college/degree [ $\geq 16$ yrs education]; A-level [13yrs education]; O-level [up to 11 years education]; CSEs or equivalent; National Vocational Qualifications/ Higher National Diploma or equivalent; other professional qualification; none), and self-reported physician diagnosed heart disease and hypertension. Body weight was collected using a Tanita BC418MA body composition analyser and nurses measured standing height using a Seca height measure with the head positioned in Frankfort plane. Body mass index (BMI) was calculated as [weight (kilograms)/height (meters) squared] $\left(\mathrm{kg} / \mathrm{m}^{2}\right)$. 
Mortality follow-up

Participants were flagged by the British National Health Service Central Registry and data from death certificates was sent to UK Biobank on a quarterly basis. ${ }^{14}$ Diagnoses for the primary cause of death were based on the International Classification of Diseases Tenth (ICD-10) Revision. Codes for IHD mortality were I20-I25. The negative control outcome, accidental death, was identified from codes V01-X59 (excluding intentional self-harm [X6084], which could have plausible links with TV Viewing through possible mental health pathways).

Statistical analysis

We present baseline descriptive characteristics of the sample by TV viewing category. Cox proportional hazards regression was used to estimate associations of TV (continuous, hr/day) with IHD mortality and the negative control outcome. We performed analyses in two stages; firstly with models unadjusted, and secondly with models adjusted for age, sex, smoking, education and prevalent cardiovascular disease. These covariates were selected as they were commonly related with both IHD and negative control outcomes, and thus could be tested as potential sources of confounding driving associations of TV viewing and IHD. The proportional hazards assumption was examined by comparing the cumulative hazard plots grouped on exposure, although no appreciable violations were noted. Data were censored $16^{\text {th }}$ February 2016 and the timescale for follow-up was years based on age at death or censorship. Analyses were performed using SPSS version 22 (IBM Inc.).

\section{Results}

The initial sample comprised 502,616 participants, although after excluding missing data the analytic sample was 479,658 men and women (aged $56.5 \pm 8.0 \mathrm{yrs} ; 45.7 \%$ male). The excluded participants did not substantially differ by sex (male $42.9 \%$ ) or age ( $56.8 \pm 8.3$ yrs). 
There were 1,437 IHD deaths, and 214 accidental deaths over follow-up. Accidental deaths largely comprised of traffic accidents $(n=64)$, falls of varying causes $(n=100)$, poisoning $(n=37)$, and other miscellaneous reasons such as assault. Participants reporting greater daily TV time were older, displayed more lifestyle risk factors (more likely to be current smokers, physically inactive, obese, consume less fruit and vegetables), report a higher prevalence of cardiovascular disease, and were less likely to be degree educated (Table 1).

Several of these covariates were associated with both IHD and accidental death, including age, male sex, smoking, education and prevalent cardiovascular disease (Table 2). That the negative outcome shared a common confounding structure with our outcome of interest (IHD mortality) confirmed that accidental death was an appropriate control.

TV viewing (per $\mathrm{hr} / \mathrm{d})$ was associated with IHD (HR=1.30, 95\% $\mathrm{Cl}, 1.27,1.33)$ and accidental death $(H R=1.15 ; 1.07,1.24)$ in unadjusted models, and both associations displayed linearity (see supplement). These associations were attenuated after adjustment for confounders (age, sex, smoking, education and prevalent cardiovascular disease); IHD (HR=1.09, 95\% $\mathrm{Cl}, 1.06,1.12)$ and accidental death $(\mathrm{HR}=1.06 ; 0.98,1.15)$ with point estimates for the two outcomes considerably converged compared to the unadjusted models.

We undertook several sensitivity analyses; firstly we considered other potential negative outcome controls. A previous meta-analysis ${ }^{15}$ suggested sedentary behavior was unrelated to cancers of the breast, rectum, ovaries, prostate, stomach, esophagus, testes, renal cell. We therefore combined stomach and esophagus cancer mortality (ICD-10 C15/16;n=576 events) to employ as a second negative control. Stomach / esophagus cancer mortality was related to key covariables including age, sex, smoking and education. In the unadjusted model there was an association between TV and stomach / esophagus cancer mortality $(H R=1.18 ; 1.13,1.24)$, although attenuated in multivariable analysis $(H R=1.04 ; 0.98,1.09)$. Secondly in order to rule out another source of bias (reverse causation), we removed deaths occurring in the first 2 years of follow up ( $n=112$ IHD; $n=34$ accidental deaths excluded) 
although results were not changed; TV viewing (per hr-d) was associated with IHD (unadjusted $H R=1.28 ; 1.25,1.32$ ) and to a lesser extent with accidental death ( $H R=1.16$; $1.06,1.25)$

\section{Discussion}

Numerous studies have suggested TV viewing (a marker of sedentary behaviour) is associated with increased risk of heart disease ${ }^{4,6-9}$ although the causal plausibility remains in doubt. We replicated previous work by demonstrating an association between TV viewing and the risk of IHD mortality in a large population cohort that persisted after adjustment for covariates. However, we also demonstrated an association of similar magnitude between TV viewing and accidental death, employed as a negative control outcome as such an association would seem implausible. Given the similarity in the pattern of results between TV viewing with IHD and accidental death, we interpret this as an effect of residual confounding.

TV viewing appears to be a general marker of an unhealthy lifestyle, for example, reflecting smoking, poor diet, obesity, lack of exercise, and poor mental health. ${ }^{1}$ In particular, TV viewing is likely to replace time being physically active. Participants are likely to watch TV sitting down, and sitting per se (or lack of muscle activity) has been directly linked to poor health outcomes. Nevertheless, when sitting is disentangled from TV viewing using objective assessment the evidence is mixed..$^{16-18}$

Limitations should be noted. Firstly the negative control outcome suffered from limited events, thus our interpretation of the results relied on the direction and magnitude of point estimates, rather than statistical significance. ${ }^{19}$ Our negative control was imperfect since the confounding structure did not identically replicate that of TV-IHD. In addition, our list of covariates was not exhaustive; if the observed association between TV and the negative control was caused by an unmeasured confounder, which is not a confounder of the TV-IHD association then this may have led to spurious interpretations. Lastly, a proportion of 
accidental deaths were caused by falls and it is not inconceivable to link a sedentary lifestyle with poorer physical function leading to the possibility of higher fall risk. Nevertheless, physical activity was unrelated to accidental death. Negative control studies have potential to improve causal inference but should be used in combination with emerging approaches such as Mendelian Randomization. ${ }^{20}$

In conclusion, TV viewing reflects a pattern of unhealthy behaviours otherwise known to be associated with heart disease. This study suggests the association between TV viewing and heart disease is likely influenced by confounding. 


\section{Acknowledgements}

This research has been conducted using the UK Biobank Resource under Application Number 25813. The data are publicly available https://www.ukbiobank.ac.uk/

This study was previously presented as an abstract at the ISBNPA 2019 Annual Meeting in Prague.

\section{Sources of funding}

DD acknowledges support from Heart Foundation Australia for a Future Leader Fellowship and by the University of Sydney via a SOAR Fellowship. ES acknowledges support from the Health and Medical Research Council (APP1110526) through a Senior Research Fellowship; and support by the University of Sydney via a SOAR Fellowship. MJD is supported by a Career Development Fellowship (APP1141606) from the National Health and Medical Research Council. 


\section{References}

1. Stamatakis E, Ekelund U, Ding D, Hamer M, Bauman AE, Lee IM. Is the time right for quantitative public health guidelines on sitting? A narrative review of sedentary behaviour research paradigms and findings. Br J Sports Med. 2018 Jun 10. pii: bjsports-2018-099131. doi: 10.1136/bjsports-2018-099131. [Epub ahead of print].

2. Hu FB, Li TY, Colditz GA, Willett WC, Manson JE. Television watching and other sedentary behaviors in relation to risk of obesity and type 2 diabetes mellitus in women. JAMA 2003; 289: 1785-91.

3. Jakes RW, Day NE, Khaw KT, Luben R, Oakes S, Welch A, Bingham S, Wareham NJ. Television viewing and low participation in vigorous recreation are independently associated with obesity and markers of cardiovascular disease risk: EPIC-Norfolk population-based study. European journal of clinical nutrition 2003; 57: 1089-96.

4. Keadle SK, Moore SC, Sampson JN, Xiao Q, Albanes D, Matthews CE. Causes of Death Associated With Prolonged TV Viewing: NIH-AARP Diet and Health Study. Am J Prev Med. 2015 Dec;49(6):811-21.

5. Biddle SJH, García Bengoechea E, Pedisic Z, Bennie J, Vergeer I, Wiesner G. Screen Time, Other Sedentary Behaviours, and Obesity Risk in Adults: A Review of Reviews. Curr Obes Rep. 2017 Jun;6(2):134-147.

6. Ekelund U, Brown WJ, Steene-Johannessen J, Fagerland MW, Owen N, Powell KE, Bauman AE, Lee IM. Do the associations of sedentary behaviour with cardiovascular disease mortality and cancer mortality differ by physical activity level? A systematic review and harmonised meta-analysis of data from 850060 participants. Br J Sports Med. 2018 Jul 10. pii: bjsports-2017-098963. doi: 10.1136/bjsports-2017-098963. [Epub ahead of print] 
7. Stamatakis E, Hamer M, Dunstan DW. Screen-based entertainment time, allcause mortality, and cardiovascular events: population-based study with ongoing mortality and hospital events follow-up. J Am Coll Cardiol. 2011;57(3):292-9.

8. Dunstan DW, Barr EL, Healy GN, Salmon J, Shaw JE, Balkau B, Magliano DJ, Cameron AJ, Zimmet PZ, Owen N. Television viewing time and mortality: the Australian Diabetes, Obesity and Lifestyle Study (AusDiab). Circulation. 2010;121(3):384-91 .

9. Matthews CE, George SM, Moore SC, Bowles HR, Blair A, Park Y, Troiano RP, Hollenbeck A, Schatzkin A. Amount of time spent in sedentary behaviors and cause-specific mortality in US adults. Am J Clin Nutr. 2012;95:437-45.

10. Hamer M, Yates T, Demakakos P. Television viewing and risk of mortality: Exploring the biological plausibility. Atherosclerosis 2017; 263: 151-5.

11. Lipsitch M, Tchetgen Tchetgen E, Cohen T. Negative controls: a tool for detecting confounding and bias in observational studies. Epidemiology. 2010 May;21(3):383-8.

12. Sudlow C, Gallacher J, Allen N, Beral V, Burton P, Danesh J, et al. UK Biobank: An Open Access Resource for Identifying the Causes of a Wide Range of Complex Diseases of Middle and Old Age. PLoS Med 2015;12: e1001779.

13. Craig CL, Marshall AL, Sjorstrom M, Bauman AE, Booth ML, Ainsworth BE, Pratt M, Ekelund UL, Yngve A, Sallis JF, Oja P. International physical activity questionnaire: 12-country reliability and validity. Med Sci Sport Exerc. 2003 Aug 1;35(8):1381-95.

14. UK Biobank Mortality data: linkage from national death registries. 15 Feb 2013. http://biobank.ctsu.ox.ac.uk/crystal/docs/DeathLinkage.pdf

15. Schmid D, Leitzmann MF. Television viewing and time spent sedentary in relation to cancer risk: a meta-analysis. J Natl Cancer Inst. 2014 Jun 16;106(7)

16. Evenson KR, Wen F, Herring AH. Associations of Accelerometry-Assessed and Self-Reported Physical Activity and Sedentary Behavior With All-Cause and 
Cardiovascular Mortality Among US Adults. American journal of epidemiology $2016 ; 184: 621-32$

17. Diaz KM, Howard VJ, Hutto B, et al. Patterns of sedentary behavior and mortality in u.s. middle-aged and older adults: A national cohort study. Annals of internal medicine 2017 Oct 3;167(7):465-475.

18. Lee IM, Shiroma EJ, Evenson KR, Kamada M, LaCroix AZ, Buring JE. Accelerometer-Measured Physical Activity and Sedentary Behavior in Relation to All-Cause Mortality: The Women's Health Study. Circulation 2018 Jan 9;137(2):203-205.

19. Sterne J, Davey-Smith G. Sifting the evidence - What's wrong with significance tests? BMJ 2001: 322:226-231.

20. Doherty A, Smith-Byrne K, Ferreira T, Holmes MV, Holmes C, Pulit SL, Lindgren CM. GWAS identifies 14 loci for device-measured physical activity and sleep duration. Nat Commun. 2018 Dec 10;9(1):5257. 
Table 1. Characteristics of the sample at baseline $(n=479,658)$

\section{TV viewing}

\begin{tabular}{cllll} 
& $\begin{array}{l}\text { Up to } 1 \mathrm{hr} / \mathrm{d} \\
(\mathrm{n}=98,713)\end{array}$ & $\begin{array}{l}1-2 \mathrm{hr} / \mathrm{d} \\
(\mathrm{n}=128,673)\end{array}$ & $\begin{array}{c}2-3 \mathrm{hr} / \mathrm{d} \\
(\mathrm{n}=113,077)\end{array}$ & $\begin{array}{c}>3 \mathrm{hr} / \mathrm{d} \\
(\mathrm{n}=139,195)\end{array}$ \\
\hline $\begin{array}{l}\text { Age, years } \pm \text { SD } \\
\text { Sex, \% male }\end{array}$ & $54.4 \pm 8.1$ & $55.3 \pm 8.1$ & $56.9 \pm 7.9$ & $58.8 \pm 7.6$ \\
$\begin{array}{l}\text { Crude Mortality /1000 } \\
\text { IHD }\end{array}$ & 44.6 & 45.8 & 45.8 & 45.9 \\
Accidents & 2.2 & & & 5.5 \\
\end{tabular}

Cigarette smoking, $\%$

$\begin{array}{lllll}\text { Never } & 60.5 & 57.9 & 54.2 & 48.4 \\ \text { Ex-smoker } & 31.1 & 33.1 & 35.7 & 38.0 \\ \text { Current } & 8.4 & 9.0 & 10.1 & 13.6\end{array}$

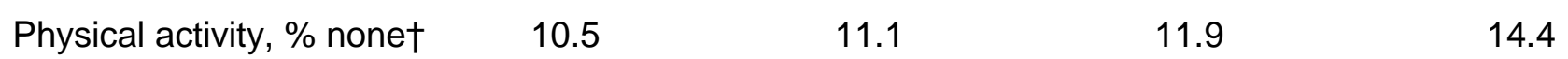

$\begin{array}{lllll}\text { Fruit \& vegetables, \% none } & 7.1 & 7.9 & 9.1 & 12.2\end{array}$

$\begin{array}{lllll}\text { Alcohol intake, \% daily } & 23.2 & 21.5 & 20.3 & 17.6\end{array}$

$\begin{array}{lllll}\text { Degree educated, \% } & 54.1 & 38.9 & 27.6 & 16.2\end{array}$

$\begin{array}{lllll}\text { Prevalent CVD } \%, \% & 20.8 & 25.5 & 30.6 & 38.3\end{array}$

Body mass index, \%

$\begin{array}{lllll}<18.5 \mathrm{~kg} / \mathrm{m}^{2} & 0.8 & 0.5 & 0.4 & 0.3 \\ 18.5-24.9 & 45.0 & 35.3 & 29.1 & 22.6 \\ 25-29.9 & 39.1 & 43.3 & 44.7 & 43.5 \\ \geq 30 & 15.1 & 20.9 & 25.8 & 33.6\end{array}$

$\dagger$ defined as no moderate to vigorous physical activity lasting at least $10 \mathrm{~min} ; \ddagger$ Prevalent cardiovascular disease (CVD) defined as physician diagnosed angina, heart attack, hypertension. 
Table 2. The confounding structure of negative outcome control and heart disease mortality outcomes.

\begin{tabular}{|c|c|c|}
\hline Measured confounders & $\begin{array}{l}\text { Accidental death } \\
\text { HR }(95 \% \mathrm{Cl})\end{array}$ & $\begin{array}{c}\text { Ischaemic heart disease } \\
\text { HR }(95 \% \mathrm{Cl})\end{array}$ \\
\hline Age (per year) & $1.04(1.03,1.06)$ & $1.11(1.11,1.12)$ \\
\hline $\begin{array}{l}\text { Sex } \\
\text { Female } \\
\text { Male }\end{array}$ & $\begin{array}{l}1.0 \text { (Ref) } \\
1.97(1.49,2.61)\end{array}$ & $\begin{array}{l}1.0 \text { (Ref) } \\
5.31(4.61,6.11)\end{array}$ \\
\hline $\begin{array}{l}\text { Smoking } \\
\text { Never } \\
\text { Ex-smoker } \\
\text { Current smoker }\end{array}$ & $\begin{array}{l}1.0 \text { (Ref) } \\
1.13(1.83,1.54) \\
3.02(2.13,4.27)\end{array}$ & $\begin{array}{l}1.0 \text { (Ref) } \\
1.65(1.46,1.87) \\
4.09(3.56,4.71)\end{array}$ \\
\hline $\begin{array}{l}\text { Physical activity quartile (MET-min/wk) } \\
1 \text { (lowest) } \\
2 \\
3 \\
4 \text { (highest) }\end{array}$ & $\begin{array}{l}1.0 \text { (Ref) } \\
0.82(0.53,1.26) \\
0.98(0.65,1.48) \\
1.18(0.80,1.75)\end{array}$ & $\begin{array}{l}1.0 \text { (Ref) } \\
0.64(0.55,0.75) \\
0.58(0.50,0.68) \\
0.63(0.55,0.73)\end{array}$ \\
\hline $\begin{array}{l}\text { Alcohol intake } \\
\text { Daily } \\
3-4 \text { times a week } \\
\text { Once a week } \\
1-2 \text { a month } \\
\text { Special occasions } \\
\text { Never }\end{array}$ & $\begin{array}{l}1.0 \text { (Ref) } \\
0.75(0.50,1.12) \\
1.04(0.72,1.51) \\
0.75(0.43,1.29) \\
0.70(0.40,1.23) \\
1.63(1.02,2.60)\end{array}$ & $\begin{array}{l}1.0 \text { (Ref) } \\
0.98(0.84,1.15) \\
1.20(1.03,1.40) \\
1.25(1.01,1.53) \\
1.71(1.42,2.06) \\
2.28(1.89,2.74)\end{array}$ \\
\hline $\begin{array}{l}\text { Fruit \& vegetables (daily serving) } \\
\text { None } \\
1 \\
2 \\
3 \\
4+\end{array}$ & $\begin{array}{l}1.0 \text { (Ref) } \\
0.80(0.50,1.29) \\
0.67(0.41,1.09) \\
0.74(0.44,1.23) \\
1.08(0.66,1.77)\end{array}$ & $\begin{array}{l}1.0 \text { (Ref) } \\
0.57(0.48,0.67) \\
0.52(0.44,0.61) \\
0.53(0.44,0.64) \\
0.62(0.52,0.75)\end{array}$ \\
\hline $\begin{array}{l}\text { Education } \\
\text { Degree } \\
\text { A-Level/O-level/GCE } \\
\text { HND/NVQ } \\
\text { Other } \\
\text { None }\end{array}$ & $\begin{array}{l}1.0 \text { (Ref) } \\
1.84(1.27,2.68) \\
1.43(0.78,2.62) \\
2.76(1.60,4.78) \\
2.25(1.49,3.42)\end{array}$ & $\begin{array}{l}1.0 \text { (Ref) } \\
1.32(1.14,1.52) \\
1.26(1.02,1.57) \\
1.24(0.96,1.61) \\
2.15(1.86,2.48)\end{array}$ \\
\hline $\begin{array}{l}\text { Cardiovascular conditions } \\
\text { None } \\
\text { Heart disease } \\
\text { Hypertension }\end{array}$ & $\begin{array}{l}1.0 \text { (Ref) } \\
1.58(0.99,2.53) \\
1.34(0.99,1.82)\end{array}$ & $\begin{array}{l}1.0 \text { (Ref) } \\
7.00(6.14,7.97) \\
1.86(1.63,2.12)\end{array}$ \\
\hline $\begin{array}{l}\text { Body mass index, } \mathrm{kg} / \mathrm{m}^{2} \\
<18.5 \\
18.5-24.9 \\
25-29.9 \\
\geq 30\end{array}$ & $\begin{array}{l}2.06(0.50,8.34) \\
1.0 \text { (Ref) } \\
0.67(0.49,0.92) \\
0.77(0.54,1.10)\end{array}$ & $\begin{array}{l}2.20(0.98,4.95) \\
1.0 \text { (Ref) } \\
1.20(1.03,1.38) \\
2.10(1.82,2.43)\end{array}$ \\
\hline
\end{tabular}

Hazard ratios (HR) are adjusted for age and sex 